UNDERGROUND MINING ENGINEERING 36 (2020) 19-28 $\quad$ UDK 62

\title{
CALCULATION THE CAPACITY OF BUCKET WHEEL EXCAVATOR THE SELECTIVE MINING OF OVERBURDEN
}

\begin{abstract}
Saša Ilić
Received: April 6, 2020

Abstract: During open pit coal exploitation inevitably comes to land degradation. The negative changes, processes and consequences impose need for parallel working on sanitation and in general arranging destroyed natural areas. The one of sanitation criterion is implementation of reclamation which has a goal to restore completely or as much as it is possible, the destroyed area to its previous purpose. The priority has consistent conducting of technical reclamation of spoil in accordance with planned landscaping.
\end{abstract}

Accepted: May 30, 2020

Keywords: bucket wheel excavator; capacity; selective overburden mining; open pit mining.

\section{INTRODUCTION}

Unified selective mining, conveyance and dumping of solum incorporates utilization of available ECS system equipment running at the top level of the open pit mine. Bucket wheel excavator running at the top level (under terrain surface) in the height block selectively mines the solum in the first cut of the height block, with the cut height equivalent to the thickness of solum, the excavator mines the fertile soil, that further on is conveyed by the existing conveyors up to the spreader at the waste dump. The spreader deposits the solum mass over the top part of the dumping mass thus forming the surface with fertile soil required for biological land-reclamation. Upon completion of one cycle of bucket wheel excavator mining of solum (deep down to the full cut depth), the excavator continues with mining of the remaining part of overburden in the height block. The spreader deposits those masses in the height block at the dump, representing a basis for the next solum laying.

\section{SELECTIVE MINING OF OVERBURDEN IN OPEN PIT MINES}

From the aspect of excavation equipment and its application possibilities has been analyzed limitations in the equipment operation for continuous systems during the selective excavation, and in case of the bucket wheel excavator, considering that it is a

${ }^{1}$ University of Belgrade - Faculty of Mining and Geology

E-mail: $\underline{\text { sasa.ilic@rgf.bg.ac.rs }}$ 
dominant element of the system, in terms and waste conveying and in terms of waste disposal, although it is necessary to provide a spreader with the suitable capacity. In this case provided bucket wheel excavator, type SRs 2000 with its structure features meet the basic requirements for the selective overburden mining application in accordance with structural parameters of the opencast mine (bench height, angle of bench slopes inclination and the operating benches system).

Excavation of overburden and at the open pit Radljevo was predicted using a continuous and discontinuous equipment.

Excavation and loading of overburden by a continuous equipment is carried out by bucket wheel excavators type SRs 2000*32/5.

In addition to these bucket wheel excavators, which are currently in the exploitation process, there is another type of a bucket wheel excavator SRs $2000 * 32$ to be included in the production as an aggregate within the II ECS system (Pavlović, Ignjatović, 2012).

Systems with bucket wheel excavator conveyor overburden by bench belt conveyors with $1,600 \mathrm{~mm}$ width, and by shifting devices material flow is being directed to connecting belt conveyors for overburden with $2,000 \mathrm{~mm}$ width, and spreader with the theoretical capacity of $8,500 \mathrm{~m}^{3} / \mathrm{h}$.

Calculated capacity values, differences of the bucket wheel excavator capacity in the cut, for the individual cuts has been established, less than $10 \%$ and as average $1.1 \%$. Some difference occurs due to some differences in operating parameters. Optimal block design parameters are used in the model and as real at the field, before all in relation to the turning angle of the rotor mast. In this way, it has been established that the used model can be efficiently used for the capacity calculation of the bucket wheel excavator in the selective mining of overburden.

Since at the part of "Radljevo" deposit there is no experience in coal mining, even in the application of selective mining, some basic indicators of present selective mining feasibility study on selective mining and dumping of overburden.

Capacity calculation of excavation equipment has been performed for the opencast mine "Radljevo" in line with technological solutions provided by the Study on the Selection of Limitation and Opening of Opencast Mines South Field and "Radljevo". Overburden excavation has been foreseen at two benches in total, of continuous systems.

Based on the analysis of results for the total capacity of the mining system with excavators of SRs $2000 * 32 / 5$ type it has been established that envisaged connecting conveyors and spreader meet the required capacity on the excavation. In addition, on the basis of the technical capacity analysis for this main excavation equipment, it is clear that it can be applied for the selective overburden mining at the opencast mine field "Radljevo", MB "Kolubara". 
Calculation of capacity has been made, according to the soil-mechanical characteristics of the working environment, for the resistance values and resistance of overburden removal from $400-800 \mathrm{~N} / \mathrm{cm}$. For the individual typical cases calculated capacity values have been interpreted at the area of individual benches and beside the capacity values provided in tables. Capacities are calculated for the case of the selection level $2.5 \mathrm{~m}$. Analysis has included capacity calculation for excavator type SRs 2000, which is to be involved at benches 1 of ECS system with selective mining of fertile soil in function of waste dump land reclamation, consists of.

Presented analysis is bucket wheel excavators capacity analysis of different classes in the block, without taking into account the time for material flow exchanging (overburden-solum) at the bench belt conveyors, and other technological processes (cutting to a new block, time for shifting of belt conveyors and other). Exactly at these technological operations there is significant difference between.

In addition to reducing the time available overburden excavation, excavate it must be cut, the amount of which is not sufficient for achieving the required capacity. It is known from the theory of the bucket wheel excavator digging the height of cut should be 0.50.7 diameter of working wheel. This recommendation is just because with such cutting height achieved good filling buckets, or the necessary capacity. But it often happens that it is necessary to dig up the cut, whose height is insufficient to achieve the desired goal. This entails, of course, entails loss of load excavator due to the inability to compensate small cutting height, the maximum possible thickness and width of the steak.

The fall in the capacity of an excavator in such cases imposes the need to compensate for the backhoe, to ensure the road of development works in progress. On the other hand, the small size, bucket wheel excavator digging out a layer of small thickness Solum time much longer than is the case in normal operation. The consequences of this is also the problem of compensation falls excavator capacity in the long run.

On the open pit "Radljevo" Study limitations choice and opening of open pits "Radljevo" and "South Field" with comparative presentation of techno-economic aspects of coal exploitation for the selection of priority coal supplier TE-TO Kolubara B (Vattenfall Europe Mining AG, Mining and Geology University of Belgrade, 2008) variant of digging coal with an annual capacity of 13 million tons is planned excavation of overburden from the two systems. Two BTO system comprised of bucket wheel excavator theoretical capacity of $7000 \mathrm{~m}^{3} / \mathrm{h}$. It is anticipated that the disposal of tailings is carried trays with tape, the theoretical capacity of 14000 and $8800 \mathrm{~m}^{3} / \mathrm{h}$. 


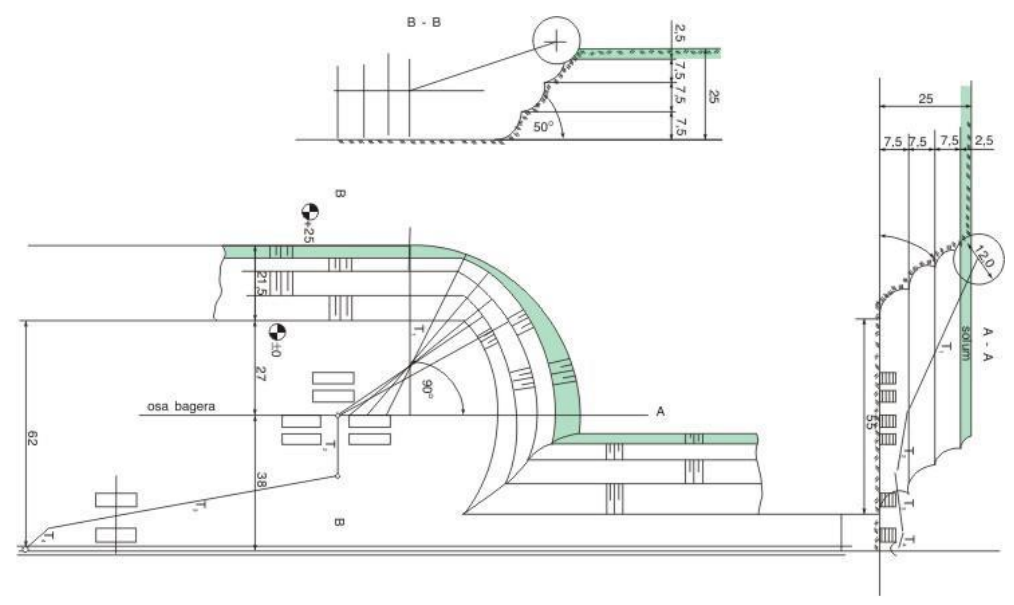

Figure 1 Principal scheme of a bucket wheel excavator SRs 2000*32/5 running during the selective mining of the fertile soil, I block (Vujić S. et al, 2004)

For a maximum digging height of $32 \mathrm{~m}$, the block is divided into five sections $(8 \mathrm{~m}+7 \mathrm{~m}$ $+7 \mathrm{~m}+7 \mathrm{~m}+3 \mathrm{~m}$ ). According to the pedologists, the fertile soil layer is up to $2.5 \mathrm{~m}$ below the surface of the terrain. Due to the safe lifting height of the working wheel, the height of the floor is reduced to $25 \mathrm{~m}$ during selective digging. The first cut is $2.5 \mathrm{~m}$ high, the other three are $7.5 \mathrm{~m}$ each.

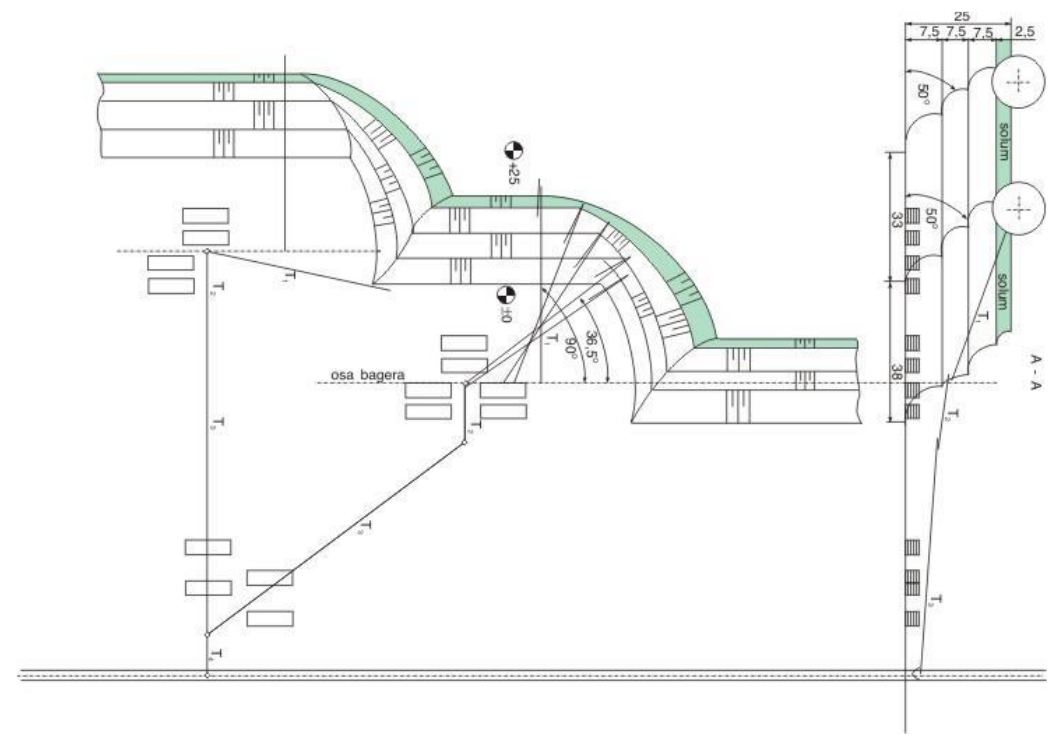

Figure 2 Principal scheme of a bucket wheel excavator SRs $2000 * 32 / 5$ running during the selective mining of the fertile soil, II and III block (Vujić S. et. al, 2004) 


\section{CAPACITY THE BUCKET WHEEL EXCAVATORS}

Procedure of calculation the capacity of bucket wheel excavator on overburden was carried out according to the methodology presented in the following text.

Border angle of regulation:

$$
\cos \xi_{r l}=\frac{q \cdot n}{h_{I} \cdot s_{I} \cdot k_{r} \cdot v_{b o, \max }}
$$

where:

q - volume of bucket, 1.000 [1]

$\mathrm{n}$ - number of bucket discharging $86\left[\mathrm{~min}^{-1}\right]$

$h_{I^{-}}$sublevel height $2.5[\mathrm{~m}]$

$V_{\text {bmax }}$ - maximum speed of boom rotation, $30[\mathrm{~m} / \mathrm{min}]$

$s_{I}$ - maximum thickness of slice, $[0.7 \mathrm{~m}]$

The basic rotation speed of bucket wheel carrier:

$$
v_{b o I}=\frac{q \cdot n}{h_{i} \cdot s \cdot k_{r}}
$$

The medium rotation speed of bucket wheel carrier:

$$
v_{b s I}=\frac{\xi_{u I}+\xi_{s I}}{\frac{57,3 \cdot\left(\sin \xi_{r I}+\sin \xi_{s I}\right)}{v_{b o I}}+\frac{\xi_{u I}-\xi_{r I}}{v_{b o, \text { max }}}}
$$

where:

$\xi_{u I^{-}}$turning angle of rotor boom in a sublevel towards the inside lateral slope (90 for the I sublevel)

$\xi_{s I}$ - turning angle of rotor boom in a sublevel towards the outer lateral slope $\xi_{r I^{-}}$angle regulation in a sublevel

The medium time of rotation of wheel carrier:

$$
t_{s I}=\frac{\pi \cdot\left(L_{s} \cdot e_{1} \cdot \frac{D}{2}\right) \cdot\left(\xi_{u I}+\xi_{s I}\right)}{180^{\circ} \cdot v_{b s I}}
$$


where:

$\mathrm{L}$ - boom length, [m]

e - horizontal distance the pivot point of rotary boom from vertical axis of excavator rotation, $[\mathrm{m}]$

$\mathrm{D}$ - radius of operating wheel, $[\mathrm{m}]$

Time of cut change in a block:

$$
t_{r b I}=\frac{s_{I}}{v_{t r}}
$$

Where:

$s_{I^{-}}$maximum thickness of cut, [m]

$v_{t r}$ - transport speed of excavator, $[\mathrm{m} / \mathrm{min}]$

Number of cuts in a sublevel is determined according to the relationship:

$$
t_{e t}=\frac{Z-s_{\text {max }}+\frac{h_{i}}{\tan \beta_{\check{c}}}}{v_{t}}
$$

Volume of a block:

$$
V_{j}=H_{j} \cdot B_{b} \cdot Z
$$

Technical capacity of a bucket wheel excavator for defined technological parameters is:

$$
Q_{t h}=\frac{Q_{t}}{k_{r}} \cdot k_{b} \cdot k_{o}
$$

Calculated excavator capacity by individual ECS system at selective operation:

Field "Radljevo"

Overburden-Selective Mining

Analysis by input it block parameters

Work excavators in blocks

$\begin{array}{ll}\text { Gamma of material } & 17,00\left[\mathrm{kN} / \mathrm{m}^{3}\right] \\ \text { Cutting resistance } & 400,00[\mathrm{~N} / \mathrm{cm}]\end{array}$


BWE - SRs 2000

Bench height: $25[\mathrm{~m}]$

Beta 1-upper: 90 [deg.]

Beta 2-lower: 35 [deg.]

Front slope angle: 65 [deg.]

Side slope angle: 60 [deg.]

Solid-to-broken ratio: 1.20

Bench height - $25 \mathrm{~m}$ (Number bands- 4)

Block width $-53.58 \mathrm{~m}(\mathrm{~B} 1=90 \mathrm{~B} 2=35)$

Table 1 Block parameters for selective mining

\begin{tabular}{cccccccccc}
\hline Br. & $\begin{array}{c}\mathrm{H} \\
{[\mathrm{m}]}\end{array}$ & $\mathrm{N}$ & $\begin{array}{c}\mathrm{LB} \\
{[\mathrm{m}]}\end{array}$ & $\begin{array}{c}\mathrm{B} \\
{[\mathrm{m}]}\end{array}$ & $\begin{array}{c}\mathrm{B} 1 \\
{[\mathrm{deg} .]}\end{array}$ & $\begin{array}{c}\mathrm{B} 2 \\
{[\mathrm{deg} .]}\end{array}$ & $\begin{array}{c}\mathrm{V} \\
{[\mathrm{bcm}]}\end{array}$ & $\begin{array}{c}\mathrm{T} \\
{[\mathrm{min}]}\end{array}$ & $\begin{array}{c}\mathrm{Q} \\
{[\mathrm{bcm}]}\end{array}$ \\
\hline 1 & 25.00 & 4 & 20.65 & 67.73 & 90 & 35 & 34966.60 & 576.50 & 3639.00 \\
2 & 25.00 & 4 & 20.65 & 67.73 & 90 & 35 & 34966.60 & 576.50 & 3639.00 \\
52 & 25.00 & 4 & 20.65 & 67.73 & 90 & 35 & 34966.60 & 576.50 & 3639.00 \\
53 & 25.00 & 4 & 20.65 & 67.73 & 90 & 35 & 34966.60 & 576.50 & 3639.00 \\
\hline
\end{tabular}

Capacity $(\mathrm{Vb} / \mathrm{Tb})-3639.20 \mathrm{bcm} / \mathrm{h}$

(1 $853229.80 \sim \mathrm{m}^{3}$ : $\left.509.24 \mathrm{~h} \quad 30554.50 \mathrm{~min}.\right)$

1. band $-2.50 \quad \mathrm{~d}=0.60 \mathrm{~m} \quad 420 \mathrm{KW} \quad 400.0 \mathrm{~N} / \mathrm{cm}$

2. band - $7.50 \quad \mathrm{~d}=0.60 \mathrm{~m} \quad 962 \mathrm{KW} \quad 400.0 \mathrm{~N} / \mathrm{cm}$

3. band - $7.50 \quad \mathrm{~d}=0.60 \mathrm{~m} \quad 962 \mathrm{KW} \quad 400.0 \mathrm{~N} / \mathrm{cm}$

4. band - $7.50 \quad \mathrm{~d}=0.60 \mathrm{~m} \quad 962 \mathrm{KW} \quad 400.0 \mathrm{~N} / \mathrm{cm}$

Field "Radljevo"

Overburden-no-Selective Mining

Analysis by input it block parameters 
Work excavators in blocks

Gamma of material: $17,00[\mathrm{kN} / \mathrm{m} 3]$

Cutting resistance: $400,00[\mathrm{~N} / \mathrm{cm}]$

BWE - SRs 2000

Bench height: $25[\mathrm{~m}]$

Beta 1-upper: 90 [deg.]

Beta 2-lower: 35 [deg.]

Front slope angle: 70 [deg.]

Side slope angle: 60 [deg.]

Solid-to-broken ratio: 1.20

Bench height - 22.7m (Number bands- 4)

Block width $-69.51 \mathrm{~m}(\mathrm{~B} 1=90 \mathrm{~B} 2=35)$

Solid-to-broken ratio: 1.20

Table 2 Block parameters no selective mining

\begin{tabular}{cccccccccc}
\hline Br. & $\begin{array}{c}\mathrm{H} \\
{[\mathrm{m}]}\end{array}$ & $\mathrm{N}$ & $\begin{array}{c}\mathrm{LB} \\
{[\mathrm{m}]}\end{array}$ & $\begin{array}{c}\mathrm{B} \\
{[\mathrm{m}]}\end{array}$ & $\begin{array}{c}\text { B1 } \\
{[\mathrm{deg} .]}\end{array}$ & $\begin{array}{c}\mathrm{B} 2 \\
{[\mathrm{deg} .]}\end{array}$ & $\begin{array}{c}\mathrm{V} \\
{[\mathrm{bcm}]}\end{array}$ & $\begin{array}{c}\mathrm{T} \\
{[\mathrm{min}]}\end{array}$ & $\begin{array}{c}\mathrm{Q} \\
{[\mathrm{bcm}]}\end{array}$ \\
\hline 1 & 25.00 & 4 & 20.65 & 67.73 & 90 & 35 & 34966.60 & 495.76 & 4231.80 \\
2 & 25.00 & 4 & 20.65 & 67.73 & 90 & 35 & 34966.60 & 495.76 & 4231.80 \\
60 & 25.00 & 4 & 20.65 & 67.73 & 90 & 35 & 34966.60 & 495.76 & 4231.80 \\
61 & 25.00 & 4 & 20.65 & 67.73 & 90 & 35 & 34966.60 & 495.76 & 4231.80 \\
\hline
\end{tabular}

Capacity (Vb /Tb) - 4231,88 bcm/h

Analysis by input it block parameters

Work excavators in blocks

Bench height - $25 \mathrm{~m}$ (band - 4)

Block width $-53.58 \mathrm{~m}(\mathrm{~B} 1=90 \mathrm{~B} 2=35)$

1. band-6.25 d = $0.60 \mathrm{~m} \quad 849 \mathrm{KW} \quad 400.0 \mathrm{~N} / \mathrm{cm}$ 

2. band - $6.25 \mathrm{~d}=0.60 \mathrm{~m} \quad 849 \mathrm{KW} \quad 400.0 \mathrm{~N} / \mathrm{cm}$
3. band - $6.25 \mathrm{~d}=0.60 \mathrm{~m} \quad 849 \mathrm{KW} \quad 400.0 \mathrm{~N} / \mathrm{cm}$
4. band- $6.25 \mathrm{~d}=0.60 \mathrm{~m} \quad 849 \mathrm{KW} \quad 400.0 \mathrm{~N} / \mathrm{cm}$

The block height of the bucket wheel excavator with selective mining of fertile soil is reduced between 5 and $10 \%$, depending on the working wheel. By reducing the height of the first cut to the thickness of the fertile soil, the capacities of the bucket wheel excavator are also reduced. The analysis shows that the entire capacity of the bucket wheel excavator in the height block, during selective mining of the fertile soil (ECS SRs 2000), reduced for $14,5 \%$. With conveyance during the selective mining of the fertile soil, no changes occur, except the reduced utilization of the installed capacity in the phase of fertile soil mining, that otherwise reduces the entire capacity efficiency of the ECS system by the same percentage appearing with the bucket wheel excavator.

\section{CONCLUSIONS}

The level of analysis, and reliability final results represent safe grounds for support in decision-making and good mark for further solving of the urgent problem of landreclamation, revitalization and spatial arrangement of degraded surface in coal basin field "Radljevo".

Analysis of possible technological solutions of selective mining, conveyance and overburden dumping at the open pit mines without exceptions shows that the unified, namely existing technology with the ECS systems, adjusted for selective work, has an enormous advantage in relation to separated (individual technological process of mining of fertile soil at the open pit mine) technologies and that the same provides for the respective efficiency of financial investments.

The analysis also demonstrates that the transfer from the existing manner of work to the selective requires primarily changes in the domain of organization and work discipline whereby, at the same time, may be indemnified the falls in capacity of bucket wheel excavators due to their technical-technological non-adjustment for small cut heights.

\section{REFERENCES}

DREBENSTEDT, C. and STRUZINA, M.: (2008) Overburden Management for Formation of Internal Dumps in Coal Mines. In AB Fourie (ed.): Proceedings of the First International Seminar on the Management of Rock Dumps, Stockpiles and Heap Leach Pads, Perth, 2008. Perth, Australian Centre for Geomechanics, pp.139-146. 
PAVLOVIĆ, V. and IGNJATOVIĆ, D. (2012) Selective opencast coal mining by continuous systems, University of Belgrade Faculty of Mining and Geology, ISBN 97886-7352-217-3.

Study limitations choice and opening of open pits "Radljevo" and "South field" with comparative presentation of techno-economic aspects of coal exploitation for the selection of priority coal supplier MB Kolubara B, Vattenfall Europe Mining AG, (2008), Mining and Geology University of Belgrade

VUJIĆ, S. et al. (2004) Feasibility study on selective mining and dumping of overburden, Academy of Engineering Sciences of Serbia and Montenegro, pp. 89-120. 